\title{
Correction to: Think Tanks: New Organizational Actors in a Changing Swedish Civil Society
}

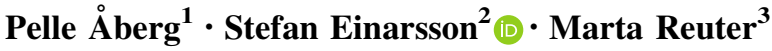

Published online: 6 October 2020

(C) International Society for Third-Sector Research 2020

\section{Correction to: Voluntas \\ https://doi.org/10.1007/s11266-019-00174-9}

In the captions for Figures 1 and 2, a reference was inadvertently omitted. The correct captions should read:

Fig. 1: Institutional dimensions of civil society functions, modified from Wijkström (2011)

Fig. 2: Changes in civil society and the policy-making system in Sweden (see Wijkström 2011 for a similar discussion on the increased importance of philanthropy in Swedish civil society)

Publisher's Note Springer Nature remains neutral with regard to jurisdictional claims in published maps and institutional affiliations.

Pelle Åberg, Stefan Einarsson and Marta Reuter have contributed equally to this article.

The original article can be found online at https:// doi.org/10.1007/s11266-019-00174-9.

Stefan Einarsson

stefan.einarsson@hhs.se

Pelle Åberg

pelle.aberg@esh.se

Marta Reuter

marta.reuter@statsvet.su.se

1 Ersta Sköndal Bräcke University College, Stockholm, Sweden

2 Stockholm School of Economics, Stockholm, Sweden

3 Stockholm University, Stockholm, Sweden 